\title{
Doping in sport: Attitudes, beliefs and knowledge of competitive high-school athletes in Gauteng Province
}

\author{
K Nolte, ${ }^{1} \mathrm{PhD}$; B J M Steyn, ${ }^{2}$ DPhil; P E Krüger, ${ }^{1} \mathrm{PhD} ;$ L Fletcher, ${ }^{3} \mathrm{PhD}$ \\ ${ }^{1}$ Department of Physiology, Division: Biokinetics and Sport Science, University of Pretoria, South Africa \\ ${ }^{2}$ Department of Sport and Leisure Studies, University of Pretoria, South Africa \\ ${ }^{3}$ Department of Statistics, University of Pretoria, South Africa \\ Corresponding author: K Nolte (kim.nolte@up.ac.za)
}

Objective. To determine the attitudes, beliefs and knowledge of talented young athletes residing in Gauteng regarding prohibited performance-enhancing drugs (PEDs) and anti-doping rules and regulations.

Methods. This was a survey study using a quantitative research approach. South African TuksSport academy athletes at the High Performance Centre, University of Pretoria, and competitive high-school athletes at four private high schools in Gauteng completed the survey. A selfdetermined, structured questionnaire was used to establish the attitudes, beliefs and knowledge of the athletes.

Results. A total of 346 (208 males, 138 females) athletes, mean (standard deviation) age 16.9 (1.4) years participated in the survey. According to this survey, $3.9 \%$ of the athletes in this survey admitted to using a prohibited PED and more than $14.0 \%$ of the athletes said they would consider using a prohibited PED if they knew they would not get caught. Ambition (46.0\%) and emotional pressure (22.5\%) were the primary reasons why the athletes would consider using prohibited PEDs. Even though coaches appeared to be one of the main sources of information (on PEDs and anti-doping rules), only $42.1 \%$ of the athletes felt that they were well informed.

Conclusion. Controlling doping by means of testing is important. However, it may be necessary to put more emphasis on changing attitudes towards doping and implementing additional educational programmes.

S Afr J SM 2014;26(3):81-86. DOI:10.7196/SAJSM.542 


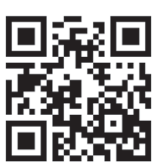

The use of prohibited substances and methods is a well-known and complex problem in sport today. ${ }^{[1]}$ The concern is not only in South Africa (SA), but is widespread across the world. ${ }^{[2]}$ In sport, the use of prohibited substances or methods to enhance performance is collectively referred to as 'doping. It is banned by both national and international sports governing bodies, and the World Anti-Doping Agency (WADA), which runs an extensive testing programme and initiatives designed to foster anti-doping attitudes. ${ }^{[3]}$ The main focus in controlling doping has been on testing athletes and the development of tests to detect usage. Although athletes' beliefs and values are known to influence whether or not they will use prohibited performance-enhancing drugs (PEDs), little is known of their beliefs and attitudes, and the limited empirical literature shows little use of behavioural science frameworks to guide research methodology, results interpretation and intervention implications. ${ }^{[2]}$ Furthermore, limited research has focused on this aspect of doping specifically with regard to SA athletes. A study was conducted in 1992 on androgenic anabolic steroid (AAS) use in matric pupils in the Western Cape ${ }^{[4]}$ and more recently Gradidge et al. ${ }^{[5]}$ investigated the attitudes and perceptions towards performanceenhancing substance use in Johannesburg boys' high-school sport.

Therefore, the primary objective of this research was to determine the attitudes, beliefs and knowledge of talented young SA athletes residing in Gauteng Province regarding prohibited PEDs and anti-doping rules and regulations. This information may lead to a better understanding of the psychosocial aspect of doping in sport and the development of efficient prevention strategies.

\section{Methods}

This was a survey study using a quantitative research approach. Ethical clearance for this study was obtained from the Postgraduate and Ethics Committee of the Faculty of Humanities, University of Pretoria, SA. SA TuksSport academy athletes at the High Performance Centre, University of Pretoria, and competitive high-school athletes from four private high schools in Gauteng completed the survey. A self-determined, structured questionnaire was used to establish the attitudes, beliefs and knowledge of the athletes with regards to PEDs. Initially, a pilot study was conducted on 10 academy athletes, after which a few minor adjustments were made to the questionnaire, considering the feedback received from the athletes, in order to ensure that the questionnaire was user friendly and that the athletes understood all the questions. The questionnaire comprised 15 questions along a six-point Likert scale. Participants signed an informed consent and assent form (parents or guardians signed on behalf of athletes aged $<18$ years) to participate in the study. Participants were given clear instructions on how to complete the questionnaire and anonymity was ensured in order to allow for the participants to answer the questions as openly and honestly as possible. Statistical analysis (standard descriptive statistics) was conducted using SPSS Statistics 20 (IBM, USA).

\section{Results}

A total of 346 athletes (208 males, $138 \mathrm{fe}$ males), mean (standard deviation (SD)) age 16.9 (1.4) years, volunteered to participate in the study. The athletes participated in various sports. Soccer was the most (28.5\%) represented sport from the sample (Table 1). More than $32.0 \%$ of the participants had been participating in their respective sport for $>8$ years. Results of the questionnaire are presented in Table 2.

Table 1. Participation of the sample in sports

\begin{tabular}{ll}
\hline Sport & $\%$ \\
\hline Soccer & 28.5 \\
Cricket & 10.3 \\
Swimming & 9.2 \\
Hockey & 8.7 \\
Athletics & 8.3 \\
Golf & 7.1 \\
Rugby & 6.0 \\
Netball & 5.5 \\
Tennis & 4.4 \\
Squash & 3.7 \\
Table tennis & 3.7 \\
Gymnastics & 2.1 \\
Other & 0.2
\end{tabular}

\section{Discussion}

More than $14.0 \%$ of the athletes said that they would consider using a prohibited PED if they knew that they would not get caught. This percentage dropped to $9.9 \%$ if there was a possibility of being tested and the PED detected. These results confer with the results of Bloodworth and McNamee, ${ }^{[3]}$ who found that a significant minority of British athletes participating in the study entertained the possibility of taking banned hypothetical PEDs under conditions of guaranteed success and undetectability. Therefore, it appears that higher chances of getting caught for using PEDs by means of successful interventions by relevant authorities, e.g. in and out of competition testing, do act as a deterrent to athletes. However, from our results, almost as many as $10.0 \%$ of athletes would still take the risk. Waddington et al. ${ }^{[6]}$ found that $73.0 \%$ of professional footballers believed that drug testing deterred drug use, and more than half believed that punishments for being caught using a PED or illicit drug were correct. Another study, conducted on elite athletes in Australia, found that athletes endorsed drug testing as an effective means of deterring drug use. They perceived a difference between being detected using a PED and an illicit drug, and believed that penalties should reflect this difference. ${ }^{[7]}$ Thus, effective testing continues to be an important component of anti-doping initiatives. Another significant deterrent associated with successful testing is the shame associated with doping. ${ }^{[3]}$

In a review conducted on doping in sport, it was found that initial reasons given for using prohibited PEDs included achievement of athletic success by improving performance, financial gain, improving recovery and prevention of nutritional deficiencies, as well as the idea that others use them, or the 'false consensus effect. ${ }^{\text {[1] }}$ Ambition (46.5\%) seemed to be the primary reason why our sample of SA athletes would take the risk of using prohibited PEDs, followed by emotional pressure $(22.5 \%)$ and then financial pressure (11.3\%). Pressure from parents to excel appeared to contribute substantially to the emotional pressure these athletes feel. Therefore, parents should be made aware of the effect this pressure can have on their children. In this study, financial pressure was rated relatively low. However, this is not surprising considering that 
Table 2. Attitudes, beliefs and knowledge regarding PEDs and anti-doping rules and regulations

Response $\%$

Q1: I would consider using a legal substance or method, e.g. special diet to improve my sports performance.

Strongly disagree

Moderately disagree

Slightly disagree $\quad 7.3$

Slightly agree $\quad 11.1$

$\begin{array}{ll}\text { Moderately agree } & 20.5\end{array}$

Strongly agree $\quad 39.0$

Q2: I would consider using a prohibited substance or method, e.g. anabolic steroids to improve my sports performance, if I knew I would not get caught out.

Strongly disagree

$\begin{array}{ll}\text { Moderately disagree } & 8.5\end{array}$

$\begin{array}{ll}\text { Slightly disagree } & 6.7\end{array}$

$\begin{array}{ll}\text { Slightly agree } & 6.7\end{array}$

$\begin{array}{ll}\text { Moderately agree } & 1.8\end{array}$

Strongly agree $\quad 6.4$

Q3: I would consider using a prohibited substance or method to improve my sports performance even if I knew there was a chance that I may get caught out.

Strongly disagree

$\begin{array}{ll}\text { Moderately disagree } & 6.9\end{array}$

$\begin{array}{ll}\text { Slightly disagree } & 3.0\end{array}$

$\begin{array}{ll}\text { Slightly agree } & 5.7\end{array}$

$\begin{array}{ll}\text { Moderately agree } & 2.7\end{array}$

Strongly agree $\quad 1.5$

Q4: If you slightly agreed (4), moderately agreed (5) or strongly agreed (6) to question Q2 or Q3, please state the reason. You may select more than one answer.

4.1 Ambition
4.2 Finncial

$\begin{array}{ll}4.2 \text { Financial pressure } & 11.3\end{array}$

$\begin{array}{lr}4.3 \text { Emotional pressure } & 22.5\end{array}$

$\begin{array}{ll}\text { 4.4 Other (please specify) } & 19.7\end{array}$

Q5: I currently use a legal substance or method, e.g. nutritional supplement to improve my sports performance.

$\begin{array}{ll}\text { Strongly disagree } & 45.5\end{array}$

$\begin{array}{ll}\text { Moderately disagree } & 6.0\end{array}$

$\begin{array}{ll}\text { Slightly disagree } & 3.6\end{array}$

$\begin{array}{ll}\text { Slightly agree } & 13.5\end{array}$

$\begin{array}{ll}\text { Moderately agree } & 11.7\end{array}$

$\begin{array}{ll}\text { Strongly agree } & 19.8\end{array}$

Q6: If you slightly agreed (4), moderately agreed (5) or strongly agreed (6) to question Q5, please identify the substance or method you currently use. You may select more than one answer.

6.2 Specialist advice, e.g. sport scientist or dietician
6.3 Speciaist eetipm

$\begin{array}{ll}6.3 \text { Specialist equipment or training techniques } & 31.7\end{array}$

$\begin{array}{lr}6.4 \text { Other (please specify) } & 12.4\end{array}$

Continued ... 
Table 2. Attitudes, beliefs and knowledge regarding PEDs and anti-doping rules and regulations ... (Continued)

Q7: I currently use a prohibited substance or method to improve my sports performance, e.g. anabolic steroids.

Strongly disagree

Moderately disagree

Slightly disagree

Slightly agree

Moderately agree

Strongly agree

Q8: If you slightly agreed (4), moderately agreed (5) or strongly agreed (6) to question Q7, please identify the prohibited substance or method you currently use. You may select more than one answer.

8.1 Anabolic steroids

8.2 Diuretics

8.3 Beta-2 agonists

8.4 Blood doping

8.5 Stimulants

8.6 Other

Q9: I am well informed about which substances or methods are prohibited in my sport.

Strongly disagree

Moderately disagree

Slightly disagree

Slightly agree

Moderately agree

Strongly agree

Q10: From whom do you get your information regarding doping in sport? You may select more than one answer.

10.1 Coach

10.2 Other athletes

10.3 Friends

10.4 Parents

10.5 South African Institute for Drug-free Sport

10.6 Other

Q11: Taking prohibited substances or methods is harmful to my health.

Strongly disagree

Moderately disagree

Slightly disagree

Slightly agree

Moderately agree

Strongly agree

Q12: Taking prohibited substances or methods to improve my sports performance is morally wrong.

Strongly disagree 
Table 2. Attitudes, beliefs and knowledge regarding PEDs and anti-doping rules and regulations ... (Continued)

\begin{tabular}{|c|c|}
\hline Response & $\%$ \\
\hline \multicolumn{2}{|c|}{$\begin{array}{l}\text { Q13: Enough is being done in South Africa to educate athletes regarding the implications of using prohibited substances } \\
\text { or methods. }\end{array}$} \\
\hline Strongly disagree & 21.7 \\
\hline Moderately disagree & 17.4 \\
\hline Slightly disagree & 19.6 \\
\hline Slightly agree & 21.4 \\
\hline Moderately agree & 10.4 \\
\hline Strongly agree & 9.6 \\
\hline \multicolumn{2}{|c|}{$\begin{array}{l}\text { Q14: In your opinion, what percentage of elite South African athletes are taking prohibited substances or methods to } \\
\text { improve their sports performance? }\end{array}$} \\
\hline $0-30 \%$ & 19.3 \\
\hline $31-50 \%$ & 26.6 \\
\hline $51-70 \%$ & 35.8 \\
\hline $71-90 \%$ & 17.7 \\
\hline $91-100 \%$ & 0.6 \\
\hline \multicolumn{2}{|c|}{$\begin{array}{l}\text { Q15: In your opinion, what percentage of elite athletes WORLD-WIDE are taking prohibited substances or methods to } \\
\text { improve their sports performance? }\end{array}$} \\
\hline $0-30 \%$ & 7.8 \\
\hline $31-50 \%$ & 21.1 \\
\hline $51-70 \%$ & 32.4 \\
\hline $71-90 \%$ & 32.1 \\
\hline $91-100 \%$ & 6.5 \\
\hline
\end{tabular}

these athletes are still in school and therefore rely on their parents for financial support; this may change when these athletes leave school and become responsible for their own finances. In addition, the reasons could be influenced by the sport that the athlete participates in, as some sports in SA are associated with better financial gain, such as rugby.

Forty-five per cent of the athletes admitted that they were using a 'legal' ergogenic aid. Specialist training (31.7\%) was rated highest, followed by dietary supplements $(28.9 \%)$ and specialist advice (26.9\%). The use of dietary supplements is widespread at all levels of sport. ${ }^{[8]}$ Furthermore, athletes appear to use supplements more than the general population and some take high doses that may lead to nutritional problems. ${ }^{[8]}$ 'Designer supplements' (over-the-counter supplements containing designer steroids and potent stimulants of which the contaminants are not declared on the label) are a problem in SA. ${ }^{[9]}$ This contamination may, in most cases, be the result of poor manufacturing practice, but there is some evidence of deliberate adulteration of products. ${ }^{[10]}$ There are numerous cases in SA and abroad in which athletes have been tested positive supposedly owing to designer supplements. The continuing story of nutritional supplements and doping infractions has led to a situation where most international sports bodies advise athletes to abstain from using any nutritional supplements.

Only $3.9 \%$ of the athletes who participated in this survey admitted to currently using a prohibited PED. This percentage is low and may not be a true reflection due to the fact that the athletes may have been concerned about the consequences of admitting to using a prohibited PED despite the fact that anonymity was assured. From the athletes who admitted to currently using a prohibited PED, $24.2 \%$ said they were using an AAS, followed by blood doping (17.7\%) and stimulants (17.7\%). This was not an unexpected finding since AASs are the most widely detected PEDs in sport. ${ }^{[1]}$ In a survey conducted by Alaranta et al. ${ }^{[12]}$ regarding the attitudes of elite athletes towards doping, it was found that stimulants were the most offered substance group (up to $7.0 \%$ of all the athletes) followed by AASs (4.0\%). Furthermore, it was found that athletes in different sports have a different approach to doping; the risk of doping appears to be highest in speed and power sports and lowest in motor skills-demanding sports. ${ }^{[12]}$ Team-based sports requiring motor skills could be less influenced by doping practices than individual self-paced sports. ${ }^{[3]}$

Only $42.1 \%$ of the athletes in this study felt that they were well informed about PEDs and anti-doping rules and regulations. Thus, although athletes are becoming increasingly familiar with anti-doping rules, there is still a lack of knowledge that should be remedied using appropriate educational programmes. ${ }^{[1]}$ The participants in this study appeared to get their information primarily from their coach (29.7\%), parents (19.4\%), friends (16.5\%) and other athletes (16.2\%). Only 10.5\% said that they obtain their information from the SA Institute for DrugFree Sport. These results are similar to those in other studies in which it has been found that coaches were the main influence and source of information for athletes. ${ }^{[1]}$ Furthermore, as many as $58.7 \%$ of the athletes said that not enough is being done to educate athletes regarding 
the implications of prohibited PED use in sport. Thus, increased efforts to educate athletes as well as coaches regarding the harmful effects of using PEDs, as well as the ethical or moral concerns surrounding doping, could decrease the likelihood of athletes using PEDs.

One of the major negative aspects of using PEDs is that they can be harmful to an athlete's health. In this study, as many as $14.7 \%$ of the athletes did not think that doping could have a negative effect on their health. It has been found that athletes who regard doping as a minor health risk seem to be more often associated with doping than those who regard doping as a significant health risk. ${ }^{[12]}$ Thus, this is another indication that more education is required with regard to prohibited PEDs, specifically with regard to the associated health risks.

Over $63.0 \%$ of the athletes strongly agreed that using prohibited PEDs in sport is morally wrong; however, $15.9 \%$ did not have a moral objection to doping. These results are similar to those of a study conducted on British athletes in which the athletes generally embraced those values promoted in anti-doping educational programmes, although there were some notable exceptions. ${ }^{[3]}$ The application of the Disconnected Values Model has recently been proposed to decrease doping in sport. The model is based on the premise that people are more likely to change their behaviour when they acknowledge the disconnect between their actions (negative habits) and their deepest values and beliefs. The primary purpose of the model is to assist athletes in acknowledging that taking drugs, whether for performance-enhancing or recreational purposes, is a negative habit that has benefits, but also dire costs and long-term consequences. ${ }^{[13]}$

A study led by Columbia University revealed that some Olympic coaches and athletes believe that as many as $90.0 \%$ of competitors use PEDs. ${ }^{[14]}$ In our study, the athletes were asked to indicate what percentage of elite SA athletes, as well as elite athletes worldwide, they think are using prohibited PEDs, and $51-70 \%$ was the highest rated category for both SA athletes and athletes worldwide. These high percentages are concerning, especially if young athletes perceive athletes they admire and look up to as using prohibited PEDs. Studies suggest that professional athletes exert an influence on others, particularly individuals who identify with these athletes. ${ }^{[15]}$ As mentioned previously, one reason why an athlete may decide to use prohibited PEDs is the idea that others use them - the 'false consensus effect. ${ }^{[1]}$ In addition, athletes may also not view using PEDs as cheating if they are under the impression that most other elite athletes are using prohibited PEDs to improve their performance. Therefore, it is essential that strategies be put in place to change this perception or false consensus effect.

\section{Conclusion}

Although controlling doping by means of testing is important, it is not sufficient. It is recommended that suitable interventions also be implemented with regard to changing attitudes towards doping and that a greater emphasis be placed on educational programmes, specifically focusing on the health risks of using PEDs.

\section{References}

1. Morente-Sánchez J, Zabala M. Doping in sport: A review of elite athletes' attitudes, beliefs and knowledge. Sports Med 2013;43(6):395-411. [http://dx.doi.org/10.1007/ s40279-013-0037-x]

2. Donovan RJ, Egger G, Kapernick V, Mendoza J. A conceptual framework for achieving performance enhancing drug compliance in sport. Sports Med 2002;32(4):269-284. [http://dx.doi.org/10.2165/00007256-200232040-00005]

3. Bloodworth A, McNamee M. Clean Olympians? Doping and anti-doping: The views of talented young British athletes. Int J Drug Policy 2010;21(4):276-282. [http:// dx.doi.org/10.1016/j.drugpo.2009.11.009]

4. Schwellnus MP, Lambert MI, Todd MP, Juritz JM. Androgenic anabolic steroid use in matric pupils. A survey of prevalence of use in the Western Cape. S Afr Med J 1992;82(3):154-158.

5. Gradidge P, Coopoo Y, Constantinou D. Attitudes and perceptions towards performance-enhancing substance use in Johannesburg boys high school sport. S Afr Sports Med 2010;22(2):32-36.

6. Waddington I, Malcom D, Roderick M, Naik R. Drug use in English professional football. Br J Sports Med 2005;39(4):e18. [http://dx.doi.org/10.1136/ bjsm.2004.012468]

7. Dunn M, Tjomas JO, Swift W, Burns L, Mattick P. Drug testing in sport: The attitudes and experiences of elite athletes. Int J Drug Policy 2010;21(4):330-332. [http://dx.doi. org/10.1016/j.drugpo.2009.12.005]

8. Solbal J, Marquart LF. Vitamin/mineral supplement use among athletes. A review of the literature. Int J Sport Nutr 1994;4(4):320-334.

9. South African Institute for Drug-Free Sport. Legislation to push to eradicate 'designer supplements'. Proceedings of the 12 July 2011 Supplements in Sport Symposium, 2011, Johannesburg, South Africa.

10. Maughan RJ, King DS, Lea T. Dietary supplements. J Sports Sci 2004;25:103-113. [http://dx.doi.org/ 10.1080/0264041031000140581]

11. Pandya U. Drug abuse in sport. Utox Update 2002;4(1):1-4. [http://dx.doi. org/10.1080/02640410701607395]

12. Alaranta A, Alaranta H, Holmila J, Palmu P, Pietilä K, Helenius I. Self-reported attitudes of elite athletes towards doping: Differences between type of sport. Int J Sports Med 2006;27(10):842-846. [http://dx.doi.org/10.1055/s-2005-872969]

13. Murphy S. The Sport Psych Handbook. Champaign: Human Kinetics, 2005.

14. Sullivan R. This is the Olympics on drugs. Times Magazine (US edition). New York: New York Times Company, 8 September 2000.

15. Quick BL. Applying the health belief model to examine news coverage regarding steroids in sports ABC, CBS, and NBC between March 1990 and May 2008. J Health Commun 2010;25:247-257. [http://dx.doi.org/10.1080/10410231003698929] 